\title{
KOMPARASI MATERI BACAAN AL-QUR'ĀN ANTARA RIWĀYAT HAFŞ IBN SULAIMĀN AL-KŪFĪY DENGAN RIWĀYAT WARSY 'UŚMĀN IBN SA'ĪD AL-MIŞRĪ DAN IMPLIKASINYA PADA PEMBELAJARAN BACA AL-QUR'ĀN
}

\author{
Rizal Taufik $\mathbf{S}^{1}$ \\ rizaltaufik83@gmail.com \\ ${ }^{1}$ Universitas Teknokrat Indonesia;
}

\begin{abstract}
This study discusses the similarities and differences in Al-Qur'an reading material between riwāyat Hafş Ibn Sulaimān al-Küfiy and riwāyat Warsy 'Uśmān Ibn Sa'̀̃d al-Mişrī and its implications for Al-Qur'ān reading learning. In implementing this research process, methods are used that are in harmony with the object of research, so the author uses a type of library research and is descriptive, comparative, or content analysis. In line with the type and nature of research, the data sources that I use are primary data sources, in an effort to collect data using the Library Study method. Data analysis used is qualitative data analysis. Based on the results of the study show that there are similarities and differences in the reading material between riwāyat Hafş Ibn Sulaimān al-Küfiy and riwāyat Warsy 'Uśmān Ibn Sa'̄̄d al-Mişrī as well as its implications for Al-Qur'an reading reading, namely the similarity in pronouncing makhärij alhurüf and şifat al-surat. However, there are differences in the form of verbs, iśbat, dialect differences (lahjah). Thus the difference in qirā'āt is caused by 2 (two) aspects, namely the historical aspect and the biological aspect. Implications for Al-Qur'an reading learning which includes components such as goals, material, methods, teachers and students, media and evaluation.
\end{abstract}

Keywords: Implications; Comparison; Riwāyat Hafşs Ibn Sulaimān al-Küfiy; Riwāayat Warsy 'Uśmān Ibn Sa'̄̄d al-Mişrī

\begin{abstract}
Abstrak
Penelitian ini membahas mengenai persamaan dan perbedaan materi bacaan Al-Qur'ān antara riwāyat Hafş Ibn Sulaimān al-Kūfiy dan riwāyat Warsy 'Uśmān Ibn Sa'îd al-Mişrī serta implikasinya pada pembelajaran baca Al-Qur'ān. Dalam pelaksanan proses penelitian ini, digunakan metode-metode yang selaras dengan objek penelitian, maka penulis mempergunakan jenis penelitian kepustakaan (library research) dan sifatnya adalah deskriptif, komparatif, atau analisis isi (content analysis). Sejalan dengan jenis dan sifat penelitian, maka sumber data yang penulis gunakan adalah sumber data primer, Dalam usaha mengumpulkan data menggunakan metode Studi Pustaka. Analisis data yang digunakan adalah analisis data kualitatif. Berdasarkan hasil penelitian menunjukan bahwa terdapat persamaan dan perbedaan materi bacaan antara riwāyat Hafş Ibn Sulaimān al-Kūfiy dan riwāyat Warsy 'Uśmān Ibn Sa'îd al-Mişrī serta implikasinya pada pembelajaran baca Al-Qur'ān yaitu persamaan dalam mengucapkan makhārij al-hurūf dan şifat al-huruf. Akan tetapi ada perbedaan dalam bentuk kata kerja, iśbat, perbedaan dialek (lahjah). Dengan demikian perbedaan qirā'āt disebabkan oleh 2 (dua) aspek yaitu aspek sejarah dan aspek biologis. Implikasi pada pembelajaran baca Al-Qur'ān yang meliputi komponen-komponen seperti tujuan, materi, metode, guru dan murid, media serta evaluasi.
\end{abstract}

Kata Kunci : Implikasi; Komparasi; Riwāyat Haf̧̧ Ibn Sulaimān al-Kūfiy; Riwāyat Warsy 'Uśmān Ibn Sa'̄d al-Mişrī 


\section{PENDAHULUAN}

Al-Qur'ān merupakan kitab Allah yang diturunkan kepada manusia untuk dijadikan petunjuk sekaligus menjadi pedoman yang menghantarkan jalan kebahagiaan di dunia dan akhirat. Al-Qur'ān akan memberikan petunjuk serta kesejahteraan bagi manusia jika manusia mau mempelajari, membaca dan mengajarkannya karena di dalam Al-Qur'ān mengajarkan tentang akidah, syariah dan akhlak.

Mengenai qirā' $\bar{t} t$ Ahmad Fathoni menerangkan bahwa suatu qirā'āt atau bacaan Al-Qur'ān baru dianggap sah apabila memenuhi tiga kriteria persyaratan, yaitu 1) Harus mempunyai sanad yang mutawatir, yakni bacaan itu diterima dari guru-guru yang terpercaya, tidak ada cacat, dan bersambung sampai kepada Rasulullah SAW, 2) Harus cocok dengan Rasm 'Uśmāni, dan 3) Harus cocok dengan kaidah tata bahasa Arab (A. Fathoni, 2008).

Para ulama sepakat bahwa ada tujuh bacaan yang disepakati dan inilah yang dikenal dengan qira'at sab'ah. Imam subki mengatakan bahwa:

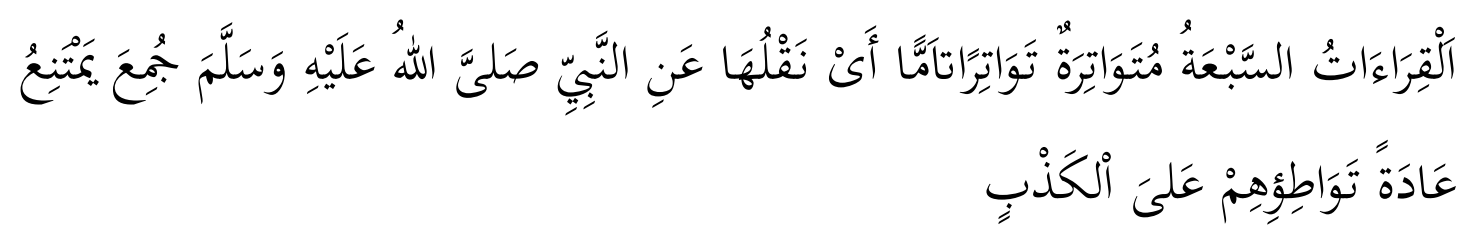

Artinya: "Qirā'āt tujuh adalah qirā'āt mutawatir yang sempurna kemutawatirannya, yakni dinukilkan dari Nabi Muhammad SAW oleh sekelompok banyak (dari sahabat) yang tidak mungkin mereka bersepakat berbohong” (Al-Qaţ̧̦ān, 2009).

Ahmad Fathoni menjelaskan bahwa Qirā' $\bar{t}$ t sepuluh adakalanya qirā'àt 'asyr şugra, yakni imam tujuh di atas ditambah tiga imam qirā'ât: Abū Ja'far, Ya'qūb, Khalaf, dan qirā'àt 'asyr kubra, yakni imam sepuluh yang dihimpun oleh Ibn al-Jazari dalam kitab al-Nasyr fi al-Qirā'āt al-'Asyr. Qirā'āt sepuluh ini menurut jumhur ulama mempunyai nilai sanad mutawatir (A. Fathoni, 2008). Ahmad bin Muhammad menjelaskan bahwa Qirā'āt empat belas adalah qirā'ātnya imam sepuluh ditambah empat imam, yaitu Hasan Basri, Ibnu Muhaishin, Yahya al-Yazidi, al-Syanbudzi. Untuk qirā'ātnya empat imam terakhir ini nilai sanadnya syadz, maka tidak boleh diakui sebagai bacaan Al-Qur'ān yang sah (Muhammad, 2000).

Setelah guru menguasai materi-materi yang akan diajarkan lalu dipilih metode apakah yang sesuai dengan materi tersebut agar dalam menyampaikan materi pelajaran 
guru dapat dengan mudah menguraikan maksud dan tujuannya. Karena metode merupakan cara yang digunakan untuk mengimplementasikan rencana yang sudah disusun dalam bentuk kegiatan nyata dan praktis untuk mencapai tujuan pembelajaran.

Metode yang penulis kenalkan adalah metode Talaqqi, yaitu suatu metode yang diajarkan oleh Rasulullah SAW serta menghubungkannya dengan metode Jibrīl, yaitu metode pembelajaran Al-Qur'ān yang diterapkan di PIQ Singosari Malang, yang dilatarbelakangi perintah Allah SWT kepada Nabi Muhammad SAW untuk mengikuti bacaan Al-Qur'ān yang telah diwahyukan melalui malaikat Jibrīl (S., 2010).

Menurut KH. M. Bashori Alwi sebagai pencetus metode Jibrīl, bahwa teknik dasar metode Jibrīl bermula dengan membaca satu ayat atau lanjutan ayat atau waqaf, lalu ditirukan oleh seluruh orang-orang yang mengaji, sehingga mereka dapat menirukan bacaan guru dengan baik. 'Utsmān Ibnu Sa'̄id al -Misrī yang dikenal dengan imam Warsy adalah seorang ulama ahli al- Qur'ān yang berasal dari Mesir, ia terkenal dengan kepandaiannya dalam membaca al- Qur'ān serta memiliki suara yang sangat merdu.

Materi yang ia ajarkan dalam membaca Al-Qur'ān meliputi dua bagian, yaitu pertama kaidah 'uşūliyyah ialah kaidah-kaidah dasar yang berlaku umum seperti kaidahkaidah cara membaca ibdal hamzah mufrod, taghlīz Lām, sukun mīm Jama’ dan şilah mīm jama', mad munfaşil, mad muttaşil, mad badal, mad lein, Iśbad ya' zaidah, altaqlīl, Naql pada al-ta'rif, tarqiq ra, al-izhar dan al-idgām. Sehingga satu kaidah dasar tersebut mencakup semua kata atau kalimat yang sejalan dengannya dan termasuk ke dalamnya.

Kedua kaidah farsy al-hurūf ialah kaidah-kaidah khusus cara membaca kata atau kalimat tertentu dalam setiap surat Al-Qur'ān seperti cara membaca ملك يوم الدين ayat 4 surat al-Fatihah. 'Āşim dan Kisā'î membaca dengan ما للك ada huruf alif setelah huruf mīm. Sedangkan lima imam lainnya (al-Baqun) membaca dengan tanpa alif, ملك dan lafazh مالك hanya boleh diberlakukan di sini saja tidak boleh diberlakukan di lafazh lain seperti di surat al-Nās. Berbeda dengan kaidah umum atau kaidah usuliyyah yang menjelaskan bacaan Imam Qirā'āt pada hukum bacaan suatu lafaz yang dapat diberlakukan dimana saja dalam Al-Qur'ān, misalnya hukum mīm jama', mad muttaşil dan lain-lain. Namun bacaan suatu lafaz yang jelas pada bab farsy al- hurūf maupun kaidah umum tidaklah bersifat mutlak, artinya penjelasan kaidah suatu lafazh tertentu 
pada surat tertentu pula pasti dibahas dalam bab farsy al-hurūf, begitu juga sebaliknya tidak semua kaidah yang bersifat umum pasti dibahas dalam bab kaidah 'uşūliyyah.

Berdasarkan penelitian terdahulu, telah dilakukan beberapa penelitian tentang studi komparasi (Anisah, 2009; M. A. Fathoni, 2017; Fatoni, 2012; Fitria, 2011; Hasanah, 2017; Mazuar \& Burhanuddin, 2012; Misdah, 2015; Muflihah, 2013; Muttaqin, 2018; Purnajaya \& Merkusiwati, 2014; Ropik, 2012; Setiawan, 2014; Setiyawan, 2016; Sofyani, Ulum, Syam, \& L., 2012; Sudewi, Subagia, \& Tika, 2014; Wagiyem, 2016; Wardhanie, 2012) dan beberapa penelitian lain tentang implikasi dalam berbagai bidang (Baharun, 2012; Emilia, 2009; Fauzan, 2018; Mawardi, 2014; Meirawan, 2010; Mukhid, 2009). Namun, masih jarang ditemukan secara khusus yang mengkaji komparasi materi bacaan Al-Qur'ān antara riwāyat Hafş ibn Sulaimān alKūfiy dan riwāyat Warsy 'Uśmān ibn Sa'̂̀d al-Mişrī serta implikasinya pada pembelajaran baca Al-Qur'ān. Maka dapat disimpulkan bahwa pembelajaran membaca Al-Qur'ān adalah sebuah proses yang menghasilkan perubahan-perubahan kemampuan melafalkan kata-kata, huruf atau abjad Al-Qur'ān yang diawali huruf a ( I ) sampai dengan ya (ي ) yang dilihatnya dengan mengerahkan beberapa tindakan melalui pengertian dan mengingat-ingat. Agar kegiatan belajar mengajar dapat berjalan dengan baik tentunya harus ada suatu sistem yang saling melengkapi satu sama lain agar tercapainya tujuan pempelajaran, seperti adanya materi yang telah dipersiapkan dan dikuasai oleh guru yang profesional, dalam hal ini guru menguasai bacaan-bacaan riwayat Warsy Utsmân Ibnu Sa'îd al-Misrî.

\section{METODE PENELITIAN}

Dilihat dari sifatnya, maka penelitian ini termasuk penelitian deskriptif, karena pada penelitian ini, para peneliti berusaha menggambarkan kegiatan penelitian yang dilakukan pada objek tertentu secara jelas dan sistematis. Penelititan deskriptif ini juga disebut penelitian praeksperimen. Karena dalam penelitian ini mereka melakukan eksplorasi, menggambarkan, dengan tujuan untuk dapat menerangkan dan memprediksi terhadap suatu gejala yang berlaku atas dasar data yang diperoleh di lapangan. Penelitian deskriptif ini hanya berusaha menggambarkan secara jelas dan sekuensial terhadap pertanyaan penelitian yang telah ditentukan sebelum para peneliti terjun ke 
lapangan dan mereka tidak benggunakan hopotesis sebagai petunjuk arah atau guide dalam penelitian.

Menurut Prasetya Irawan, dalam bukunya penelitian deskriptif adalah penelitian yang bertujuan mendeskripsikan atau menjelaskan sesuatu hal seperti apa adanya (Prasetya Irawan, 1999). Menurut Nazir menerangkan bahwa penelitian deskriptif ini juga dinamakan penelitian komparatif yaitu sejenis penelitian deskriptif yang ingin mencari jawaban secara mendasar tentang sebab-akibat, dengan menganalisis faktorfaktor penyebab terjadinya ataupun munculnya suatu fenomena tertentu (Prasetya Irawan, 1999).

Dikarenakan penelitian ini berdasarkan kepada konsep pemikiran tokoh atau ulama-ulama ahli Al-Qur'ān, sedangkan buku-buku yang dibuat langsung oleh imam Hafş Ibn Sulaimān al-Kūfiy dan imam Warsy 'Uśmān Ibn Sa'̄d al-Mişrī tidak ada, maka yang dijadikan sumber utama atau primer oleh penulis dalam kajian kepustakaan ini adalah berdasarkan Țarīq, yaitu buku: Pertama: Al-Qirā'āt al-'Asyr al-Mutawātiroh min Ţarīq al-Syaţibiyah wa al-Durroh (Syarof, 2005), Kedua: Al-Kāmil al-Mufaşşil fì alQirā'āt al-Arba'ah 'Āsyr (Al-Ma'şorowiy, 2009), Ketiga: Taqrī̄b al-Ma'āniy fì Syarh Hurz al-Amāniy fì al-Qirā'āt al-Sab' (Al-Farh \& Al-'Āmiy, 2007), Keempat: Mabāhis fì 'Ulūm Al-Qur'ān (Salih, 1977), Kelima: Pelajaran Tajwid Riwāyat Hafş (Sjafi'i, 1986). Penulis mengumpulkan data-data yang bersumberkan dari buku-buku qirā'āt Al-Qur'ān atau relevan lainnya, majalah-majalah, internet, koran atau media massa, dan dokumendokumen lainnya yang relevan fokus permasalahan penelitian ini.

Analisis data yang digunakan adalah analisis data kualitatif. Analisis data kualitatif adalah analisis yang dilakukan terhadap data-data non-angka seperti, hasil wawancara atau catatan laporan bacaan dari buku-buku, artikel, dan juga termasuk non tulisan seperti gambar, atau film (Prasetya Irawan, 1999). Menurut Bogdan dan Biklen, analisis data adalah proses mencari dan mengatur secara sistematis transkrip interview, catatan lapangan, dan bahan-bahan lain yang anda dapatkan, yang kesemuanya itu anda kumpulkan untuk meningkatkan pemahaman anda (terhadap suatu fenomena) dan membantu anda untuk mempresentasikan penemuan anda kepada orang lain (Prasetya Irawan, 1999). Tersirat dalam penjelasan ini, bahwa analisis data terkait erat dengan pengumpulan dan interpretasi data. Ini wajar, sebab analisis data dalam peneitian kualitatif berbeda dari analisis data pada penelitian lain. 


\section{HASIL KAJIAN DAN PEMBAHASAN}

Berbicara tentang Al-Qur'ān memang bagai lautan yang tak bertepi, semakin jauh ia dikejar semakin luas pula jangkauannya. Dari aspek manapun Al-Qur'ān dikaji dan diteliti, ia tidak pernah habis atau basi, bahkan semakin kaya dan selalu aktual. Mungkin itulah salah satu mukjizat yang terpancar dari kitabullah sebagai bukti kebenaran risalah Allah SWT yang dititipkan pada Rasul-Nya, yaitu al-Islam.

Aspek bacaan Al-Qur'ān atau qirā'àt dalam pengertian yang luas, bukan hanya sekedar melafadzkan huruf Arab dengan lancar, merupakan salah satu aspek kajian yang paling jarang diperbincangkan baik kalangan santri atau kaum terpelajar, padahal membaca Al-Qur'ān tergolong ibadah mahdlah yang paling utama. Hal ini barangkali bisa dimengerti, mengingat kurangnya kitab atau buku yang secara panjang lebar mengupas ilmu qirā'ât dan minimnya guru Al-Qur'ān yang memiliki kemampuan memadai tentang itu dan juga terlalu padatnya disiplin ilmu yang dipelajari. Tingginya semangat para santri mempelajari dan mencari dalīl batalnya wudhu misalnya dari AlQur'ān, hadīś dan pendapat-pendapat ulama, ternyata tidak diikuti oleh semangat mentashihkan bacaan atau mencari dalīl bacaan saktah, mad, ghunnah yang sama-sama wajib dan penting bagi kaum muslimin.

Berdasarkan fenomena di atas perlu kiranya ditumbuhkan lagi semangat untuk mengkaji aspek bacaan Al-Qur'ān yang masih misteri bagi kebanyakan orang agar kembali diminati sebagaimana begitu semangatnya anak-anak kecil di tempat-tempat pendidikan Al-Qur'ān untuk bisa membaca dengan lancar. Sebagai akibat dari kurangnya pengetahuan mereka tentang bacaan Al-Qur'ān, seringkali dianggap ilmu qirā'āt (yang dipersempit dengan ilmu tajwid) itu hanya mempelajari makhraj dan şifat huruf, hukum nūn atau mīm mati dan tanwīn, dan mad saja, sehingga mereka membaca Al-Qur'ān apa adanya sebagaimana yang terdapat dalam tulisan mushaf atau rasm, padahal ada banyak kalimat yang cara bacanya tidak sama persis dengan tulisannya, seperti bacaan imālah, tashīl, isymām dan lain sebagainya.

Dalam kesempatan ini penulis berusaha menganalisis tentang bacaan dari bacaan imam Hafş Ibn Sulaimān al-Kūfiy yang banyak dianut oleh hampir seluruh kaum muslimin sedunia, dan bacaan imam Warsy 'Uśmān Ibn Sa'îd al-Mişrī, juga alasanalasan secara bahasa tentang proses atau asal mula terjadinya bacaan tersebut. Alasanalasan kebahasaan dari bacaan Al-Qur'ān yang akan dipaparkan penulis di sini, 
hanyalah sebutir debu dibanding dari (besar dan luasnya) hikmah atau rahasia sesungguhnya yang dikehendaki Allah SWT dari perbedaan-perbedaan bacaan AlQur'ān tersebut. Dengan kata lain alasan-alasan tersebut bukanlah faktor utama yang mendorong şahibul qaul (Allah SWT) memilih kata atau lahjah tertentu, akan tetapi hanya sebuah usaha memahami rahasia-rahasia Allah melalui tanda-tanda dan ilmuilmu yang ia titipkan pada hambanya.

Seringkali argumen-argumen yang dikemukakan mengenai bentuk qirā'āt tertentu kurang relevan bila diqiyaskan dengan bacaan imam lain dalam kata yang sama atau hampir sama. Namun, dari sini justru menjadikan kita semakin meyakini bahwa perbedaan bentuk bacaan tersebut bukan hasil kreativitas imam-imam qiră'ât atau para pakar bahasa Arab di masa itu, akan tetapi mereka mewarisinya dari para sahabat, dari Nabi, dari Malaikat Jibril, dan dari Allah azza wa jalla.

Bangsa Arab merupakan komunitas terbesar dengan beragai suku termaktub di dalamnya. Setiap suku memiliki dialek (lahjah) yang khusus dan berbeda dengan sukusuku lainnya. Di sini, perbedaan lahjah itu membawa pada konsekuensi lahirnya bermacam-macam bacaan dalam melafalkan Al-Qur'ān. Oleh karena itu penelitian ini mempermasalahkan persamaan dan perbedaan materi bacaan Al-Qur'ān antara riwāyat Hafş Ibn Sulaimān al-Kūfiy dan riwāyat Warsy 'Uśmān Ibn Sa'̄d al-Mişrī. Para ulama qirā'āt mendefinisikan ilmu tajwīd adalah memberikan kepada huruf akan hak-hak dan tertibnya, mengembalikan huruf kepada makhraj dan asalnya, serta menghaluskan pengucapannya dengan cara yang sempurna tanpa belebihan, kasar, tergesa-gesa dan dipaksa-paksakan (Al-Qațţān, 2009). Berdasarkan hasil analisis, ditemukan bahwa terdapat persamaan dan perbedaan serta implikasinya terhadap bacaan antara lain:

Tabel 1.1

Persamaan Riwāyat Hafş dan Riwāyat Warsy

\begin{tabular}{|c|c|}
\hline \multicolumn{2}{|c|}{ PERSAMAAN } \\
\hline RIWĀYAT HAFŞ & RIWĀYAT WARSY \\
\hline Makhārij al-hurūf dan şifat al-hurūf & Makhārij al-hurūf dan şifat al-hurūf \\
\hline
\end{tabular}

Berdasarkan Tabel 1.1 di atas, maka persamaan dalam mengucapkan makhārij al-hurūf dan şifat al-hurūf. Dari data yang telah disebutkan bahwa tidak ditemukan suatu penjelasan bahwa ada perbedaan dalam pengucapan makhārij al-hurūf dan şifat alhurūf di antara para imam qirā'att, oleh karena itu penulis menganalisis bahwa ada 
persamaan di antara para imam qirā'āt dalam pengucapan makhārij al-hurūf dan şifat alhurūf karena ke 2 (dua) ilmu itu adalah ilmu tentang cara pengucapan huruf-huruf AlQur'ān yang dikenal dengan tajwīdul qur'ān.

Tabel 1.2

Perbedaan Riwāyat Hafş dan Riwāyat Warsy serta Sebab Bacaan Al-Qur'ān

\begin{tabular}{|c|c|c|c|c|}
\hline \multicolumn{5}{|c|}{ PERBEDAAN } \\
\hline \multirow{2}{*}{$\begin{array}{l}\text { No } \\
\dot{.} \\
1 .\end{array}$} & \multirow{2}{*}{\multicolumn{2}{|c|}{$\begin{array}{l}\text { Dalam Bentuk Kata } \\
\text { Kerja }\end{array}$}} & RIWĀYAT HAFŞ & RIWĀYAT WARSY \\
\hline & & & وَمَا يَنْدَعُوْنَ & وَمَا يُنَادِدعُوْنَ \\
\hline \multirow[t]{10}{*}{2.} & \multirow[t]{10}{*}{ Isbat } & $\begin{array}{l}\text { a. Baik ibdal } \\
\text { hamzah } \\
\text { mufrad. }\end{array}$ & 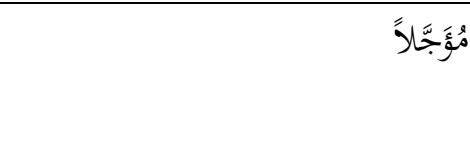 & مُوَجَّلاً \\
\hline & & \multirow{2}{*}{$\begin{array}{l}\text { b. Sukūn } \\
\text { mīm jama' } \\
\text { dan şilah } \\
\text { mīm } \\
\text { jama'. }\end{array}$} & $\begin{array}{l}\text { Mīm jama' dibaca sukūn } \\
\text { atau mati }\end{array}$ & $\begin{array}{l}\text { Mīm jama' dibaca } \\
\text { panjang } 6 \text { harakat }\end{array}$ \\
\hline & & & 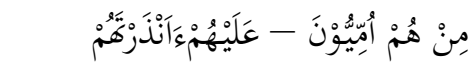 & 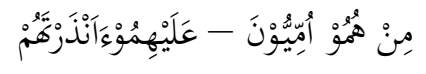 \\
\hline & & \multirow{3}{*}{$\begin{array}{l}\text { c. Mad } \\
\text { (muttaşil, } \\
\text { munfaşil, } \\
\text { badal, dan } \\
\text { layyīn). }\end{array}$} & $\begin{array}{l}\text { Mad badal dibaca panjang } \\
2 \text { harakat }\end{array}$ & $\begin{array}{lcr}\text { Mad } & \text { badal } & \text { dibaca } \\
\text { panjang } & \text { dengan } & 3 \\
\text { macam } & \text { yaitu } & 2 / 4 / 6 \\
\text { harakat } & & \end{array}$ \\
\hline & & & اَمَنَ الرَّسُولُ - لِلِِِيمَان - مَنْ اَََنَ & اَََنَ الرَّسُولُ - لِلاِِِمْانَ - مَنْ \\
\hline & & & & \\
\hline & & \multirow[t]{2}{*}{$\begin{array}{l}\text { d. Izhār dan } \\
\text { idgām. }\end{array}$} & Dibaca idgām & $\begin{array}{l}\text { Hurūf dāl dari lafaz قَّ } \\
\text { dan ta' ta'nis dibaca } \\
\text { idgām apabila bertemu } \\
\text { dengan hurūf ض- ض- }\end{array}$ \\
\hline & & & 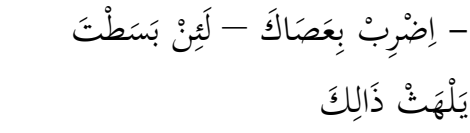 & 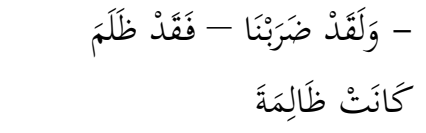 \\
\hline & & \multirow[t]{2}{*}{ e. Naql. } & $\begin{array}{l}\text { Hurūf hamzah tetap dibaca } \\
\text { sesuai harakatnya }\end{array}$ & $\begin{array}{l}\text { Memindahkan harakat } \\
\text { hamzah kepada hurūf } \\
\text { yang mati sebelum } \\
\text { hamzah }\end{array}$ \\
\hline & & & 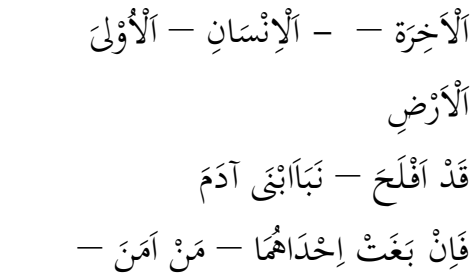 & 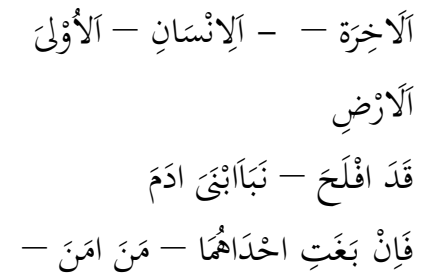 \\
\hline
\end{tabular}


E-ISSN: $2528-2476$

\begin{tabular}{|c|c|c|c|c|}
\hline & & & كُفُْوًَا آحَدُ & كُفُْوَا ححُدُ \\
\hline \multirow[t]{7}{*}{3.} & \multirow{7}{*}{$\begin{array}{l}\text { Perbe } \\
\text { daan } \\
\text { dialek } \\
\text { (lahja } \\
\text { h). }\end{array}$} & \multirow[t]{2}{*}{$\begin{array}{l}\text { a. Taghliz } \\
\text { lām. }\end{array}$} & $\begin{array}{l}\text { Hurūf lām dibaca tarqīq } \\
\text { atau berbunyi la }\end{array}$ & $\begin{array}{l}\text { Hurūf lām dibaca } \\
\text { taglīz atau berbunyi lo }\end{array}$ \\
\hline & & & 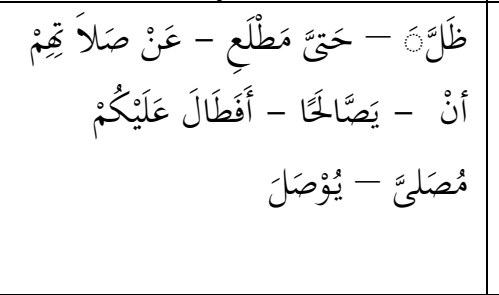 & 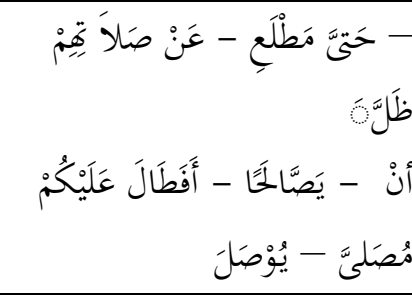 \\
\hline & & \multirow[t]{2}{*}{ b. Tarqīq ra'. } & $\begin{array}{l}\text { Hurūf ro' dibaca tafkhīm } \\
\text { /tebal yaitu tetap } \\
\text { berbunyi roo }\end{array}$ & $\begin{array}{lr}\text { Hurūf ro' } & \text { dibaca } \\
\text { tarqīq/tipis } & \text { yaitu } \\
\text { berbunyi raa } & \\
\end{array}$ \\
\hline & & & 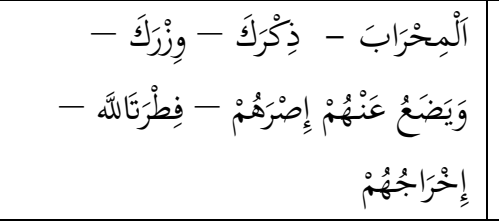 & 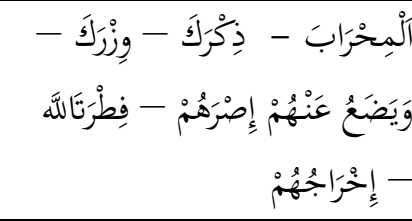 \\
\hline & & \multirow[t]{2}{*}{ c. Fathah. } & $\begin{array}{l}\text { Hurūf alif dibaca fathah } \\
\text { pada aslinya yaitu aa }\end{array}$ & $\begin{array}{l}\text { Setiap alif yang } \\
\text { asalnya dari ya' atau } \\
\text { alif ta'nis atau alif } \\
\text { yang tertulis } \\
\text { dalam masahif } \\
\text { 'uśmāniyyah dengan } \\
\text { bentuk ya' (s) dibaca } \\
\text { taqlīl } \\
\text { dan fath yaitu berbunyi } \\
\text { ree dan aa }\end{array}$ \\
\hline & & & \multicolumn{2}{|c|}{ 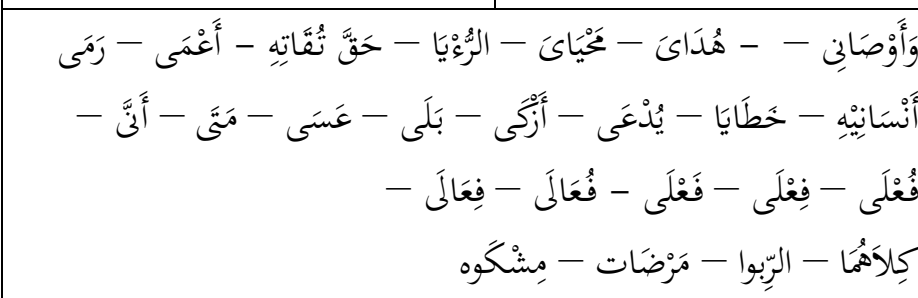 } \\
\hline & & d. Taqlīl. & $\begin{array}{l}\text { Hurūf alif dibaca pada asliny } \\
\text { yaitu aa }\end{array}$ & $\begin{array}{l}\text { Hurūf alif yang } \\
\text { terletak di setiap } \\
\text { akhir } 11 \text { (sebelas) } \\
\text { surat yakni surat } \\
\text { Ţaha, al-Najm, al- } \\
\text { Syams, al-A'la, al- } \\
\text { Laīl, al-Duhā, al- } \\
\text { 'Alaq, al-Nazi'at, } \\
\text { 'Abasa, al-Qiyāmah } \\
\text { dan al-Ma'arij, baik } \\
\text { yang asalnya ya' } \\
\text { maupun } \\
\text { wāw, dan baik yang } \\
\text { terletak sesudah ra' }\end{array}$ \\
\hline
\end{tabular}




\begin{tabular}{|c|c|c|}
\hline & & $\begin{array}{l}\text { maupun bukan } \\
\text { dibaca taqlīl } \\
\text { atau berbunyi ee }\end{array}$ \\
\hline & & 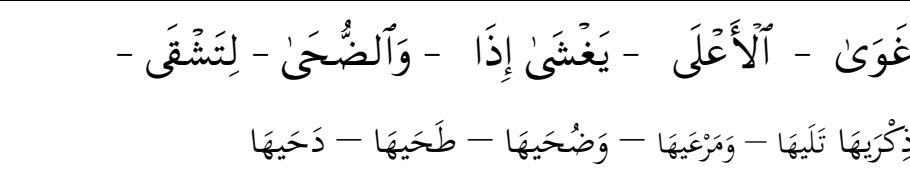 \\
\hline \multicolumn{3}{|c|}{ SEBAB PERBEDAAN BACAAN } \\
\hline & Aspek Sejarah & Aspek Biologis \\
\hline 1. & $\begin{array}{l}\text { Terdapat perbedaan bacaan } \\
\text { yang diajarkan Rasulullah } \\
\text { SAW kepada para sahabat dan } \\
\text { begitulah terus menerus } \\
\text { sahabat mengajarkan apa-apa } \\
\text { yang sudah diajarkan } \\
\text { Rasulullah SAW. }\end{array}$ & $\begin{array}{l}\text { Terdapat ilmu biolinguistik yang } \\
\text { merupakan cabang dari ilmu psikolinguistik } \\
\text { yang mengkaji bentuk-bentuk alat ujar } \\
\text { manusia yang mempengaruhi hasil bahasa } \\
\text { yang diujarkan oleh alat-alat tersebut, } \\
\text { dalam literatur dijelaskan bahwa sanad } \\
\text { periwayatan imam Hafş bersambung } \\
\text { kepada Rasulullah SAW melalui 'Alī bin } \\
\text { Abī Ţālib yang merupakan keturunan Bani } \\
\text { Hasyim, sedangkan imam Warsy } \\
\text { bersambung kepada Rasulullah SAW } \\
\text { melalui Ubai bin Ka'b dari keturunan Bani } \\
\text { Khazraj yang tentunya pengucapan mereka } \\
\text { berbeda. }\end{array}$ \\
\hline
\end{tabular}

Berdasarkan Tabel 1.2 di atas, maka perbedaan terletak dalam bentuk kata kerja. Iśbat (ibdal hamzah mufrad, sukūn mīm jama' dan şilah mīm jama', mad muttaşil, munfaşil, badal, dan layyīn, izhār dan idgām, naql). Perbedaan dialek (lahjah) baik taghliz lām, fathah, taqlīl, dan tarqīq ra'. Adanya perbedaan bacaan disebabkan oleh 2 (dua) aspek, yaitu:

a. Aspek Sejarah. Terdapat perbedaan bacaan yang diajarkan Rasulullah SAW kepada para sahabat dan begitulah terus menerus sahabat mengajarkan apa-apa yang sudah diajarkan Rasulullah SAW.

b. Aspek Biologis. Terdapat ilmu biolinguistik yang merupakan cabang dari ilmu psikolinguistik yang mengkaji bentuk-bentuk alat ujar manusia yang mempengaruhi hasil bahasa yang diujarkan oleh alat-alat tersebut, dalam literatur dijelaskan bahwa sanad periwayatan imam Hafş bersambung kepada Rasulullah SAW melalui 'Alī bin Abī Țālib yang merupakan keturunan Bani Hasyim, sedangkan imam Warsy bersambung kepada Rasulullah SAW melalui 
Ubai bin Ka'b dari keturunan Bani Khazraj yang tentunya pengucapan mereka berbeda.

Tabel 1.3

Implikasi pada Pembelajaran Baca Al-Qur'ān

\begin{tabular}{|c|c|c|}
\hline No. & \multicolumn{2}{|c|}{ IMPLIKASI PADA PEMBELAJARAN BACA AL-QUR'ĀN } \\
\hline 1. & Tujuan & $\begin{array}{l}\text { Untuk menyiapkan anak didiknya agar menjadi generasi } \\
\text { qur'āni yaitu generasi yang mencintai Al-Qur'ān, pandai } \\
\text { dalam membaca Al-Qur'ān, memiliki komitmen dengan Al- } \\
\text { Qur'ān dan menjadikan Al-Qur'ān sebagai bacaan dan } \\
\text { pandangan serta pedoman hidup. }\end{array}$ \\
\hline 2. & Materi & Qaidah uşūliyyah dan qaidah farsy al-hurūf. \\
\hline 3. & Metode & Metode Jibril \\
\hline 4. & Guru dan Murid & $\begin{array}{l}\text { Dibutuhkan seorang guru yang profesional atau ahli dalam } \\
\text { bidang qirā'at Al-Qur'ān dan menghendaki hadirnya } \\
\text { sejumlah anak didik }\end{array}$ \\
\hline 5. & Media & Al-Qur'ān muşhaf bī riwāyat Warsy \\
\hline 6. & Evaluasi & Demonstrasi atau praktek bacaan Al-Qur'ān \\
\hline
\end{tabular}

Berdasarkan Tabel 1.3 di atas, implikasi pada pembelajaran baca Al-Qur'ān yang meliputi komponen-komponen seperti tujuan untuk menyiapkan anak didiknya agar menjadi generasi qur'āni yaitu generasi yang mencintai Al-Qur'ān, pandai dalam membaca Al-Qur'ān, memiliki komitmen dengan Al-Qur'ān dan menjadikan Al-Qur'ān sebagai bacaan dan pandangan serta pedoman hidup. Materi yang diberikan dalam pelaksanaan opersionalnya dibedakan menjadi dua macam, yaitu materi qaidah uşūliyyah ialah Kaidah-kaidah dasar yang berlaku umum seperti kaidah-kaidah cara membaca mīm jama', macam-macam mad, fath, imālah, dan lain-lain sehingga satu kaidah dasar tersebut mencakup semua kata atau kalimat yang sejalan dengannya dan termasuk ke dalamnya, serta materi qaidah farsy al-hurūf ialah: Kaidah-kaidah khusus cara membaca kata atau kalimat tertentu dalam setiap surat Al-Qur'ān seperti cara ماللك ayat 4 surat al-Fātihah. 'Āşim dan al-Kisā'i membaca dengan ملك يوم الدين membaca ada huruf alif setelah mīm. Sedang lima imam lainnya membaca dengan tanpa alif.

Metode yang menurut penulis sesuai dengan pernyataan di atas adalah metode Jibril, yaitu metode yang dikeluarkan oleh KH. M. Bashori Alwi pengasuh Pesantren Ilmu Al-Qur'ān (PIQ). Intisari tehnik dari metode Jibril adalah talqin-taqlid (meniru), yaitu peserta didik menirukan bacaan gurunya. Dengan demikian, metode Jibril bersifat teacher centris, di mana posisi guru sebagai sumber belajar atau pusat informasi dalam proses pembelajaran. Metode jibril tersebut, selalu menitik beratkan pada peranan teori- 
teori ilmu tajwīd secara baik dan benar. Selanjutnya kegiatan belajar mengajar bagi seorang guru menghendaki hadirnya sejumlah anak didik. Bila tidak ada anak didik atau obyek didik, siapa yang akan diajarkan?. Hal ini perlu sekali guru sadari agar tidak terjadi kesalahan tafsir terhadap kegiatan pembelajaran.

Karena itu belajar dan mengajar merupakan istilah yang sudah baku dan menyatu dalam konsep pengajaran. Media pembelajaran adalah sarana komunikasi dalam bentuk cetak maupun pandang, dengar, termasuk teknologi perangkat keras. Dengan demikian, media merupakan alat untuk menambah serta mempermudah dalam proses belajar mengajar. Evaluasi pembelajaran merupakan salah satu bagian penting dalam sebuah kurikulum. Walaupun dalam tatanan kurikulum evaluasi berada di urutan terakhir, evaluasi berperan penting untuk menentukan sukses atau tidaknya proses pembelajaran yang dilakukan selama ini sekaligus mempengaruhi proses pembelajaran selanjutnya. Jika direfleksikan dengan fungsinya di dalam proses pembelajaran maka bisa diambil pengertian evaluasi merupakan suatu proses berkelanjutan tentang pengumpulan dan penafsiran informasi untuk menilai keputusan-keputusan yang dibuat dalam merancang suatu sistem pembelajaran. Berkaitan dengan penelitian penulis, maka evaluasi yang sesuai dengan pembelajaran baca Al-Qur'ān antara riwāyat Hafş Ibn Sulaimān al-Kūfiy dan riwāyat Warsy 'Uśmān Ibn Sa'īd al-Mişri adalah dengan cara demonstrasi yaitu mempraktekan bacaan Al-Qur'ān dengan baik dan benar.

\section{SIMPULAN DAN SARAN}

Hasil analisis yang sudah dilakukan memperlihatkan bahwa bacaan riwāyat Hafş ibn Sulaimān al-Kūfiy dan riwāyat Warsy 'Uśmān ibn Sa'īd al-Mişri terdapat persamaan dalam mengucapkan makhārij al-hurūf dan şifat al-hurūf. Akan tetapi terdapat juga perbedaan dalam bentuk tashrif kata kerja, iśbat, perbedaan dialek (lahjah) seperti ibdal hamzah Mufrad, taghliz lām, sukūn mīm jama' dan şilah mīm jama', mad (muttaşil, munfaşil, badal, dan layyīn), izhār dan idgām, fathah, imālah atau taqlīl, naql, dan tarqīq Ra'. Perbedaan bacaan disebabkan oleh 2 (dua) aspek, yaitu aspek sejarah dan aspek biologi. Serta implikasi pada pembelajaran baca Al-Qur'ān yang meliputi komponenkomponen seperti tujuan, materi, metode, guru dan murid, media dan juga yang terakhir adalah evaluasi. 


\section{DAFTAR PUSTAKA}

al-Farh, S. L. A., \& Al-'Āmiy, K. I. M. A.-H. (2007). Taqrī̄b Al-Ma'āniy Fi Syarh Hurz Al-Amāniy Fi Al-Qirā'āt Al-Sab'. Kairo: Matba'ah Al-Istiqomah.

Al-Ma'şorowiy, A. 'Īsa. (2009). Al-Kāmil Al-Mufaşşil Fi Al-Qirā'āt Al-Arba'ah 'Āsyr. Kairo: Al-Qāhirah Mesir.

Al-Qațţān, M. K. (2009). Studi Ilmu-Ilmu Qur'ān. Jakarta: Litera Antar Nusa Halim Jaya.

Anisah, S. (2009). Studi Komparasi Terhadap Perlindungan Kepentingan Kreditor Dan Debitor Dalam Hukum Kepailitan. Jurnal Hukum, 16(Edisi Khusus), 30-50.

Baharun, H. H. (2012). Desentralisasi Dan Implikasinya Terhadap Pengembangan Sistem Pendidikan Islam. Jurnal At-Tajdid, 1(1), 241-254.

Emilia, E. (2009). Pengetahuan, Sikap Dan Praktek Gizi Pada Remaja Dan Implikasinya Pada Sosialisasi Perilaku Hidup Sehat. Media Pendidikan, Gizi Dan Kuliner, $1(1), 1-9$.

Fathoni, A. (2008). Tuntunan Praktis Maqra' Babak Penyisihan Dan Babak Final Musabaqah Cabang Qirā'āt Mujawwad. Jakarta: Lptq Nasional.

Fathoni, M. A. (2017). Lindung Nilai ( Hedging ) Perspektif Islam: Komparasi Indonesia Dan Malaysia. Inferensi: Jurnal Penelitian Sosial Keagamaan, 11(2), 351-372.

Fatoni, A. (2012). Studi Komparasi Bacaan Riwayat Qalun Dan Riwayat Hafs Q.S. AlFatihah, Al-Baqarah, Dan Ali 'Imran. Suhuf, 5(1), 19-35.

Fauzan, A. (2018). Manajemen Sarana Dan Prasarana Hisbullah Natar Lampung Selatan, 3(1), 249-276.

Fitria, V. (2011). Komparasi Metodologis Konsep Sunnah Menurut Fazlur Rahman Dan Muhammad Syahrur (Perspektif Hukum Islam). Asy-Syir'ah: Jurnal Ilmu Syari'ah Dan Hukum, 45(Ii), 1335-1356.

Hasanah, S. M. (2017). Konsep Belajar Dalam Teori Konstruktivistik Dan Islam Klasik ( Komparasi Pemikiran Bobbi De Porter Dan Al-Ghazali ). Jurnal Tarbiyatuna, 2(2), 1-28.

Mawardi. (2014). Pemberlakuan Kurikulum Sd/Mi Tahun 2013 Dan Implikasinya Terhadap Upaya Memperbaiki Proses Pembelajaran Melalui Ptk. Scholaria, 4(3), 107-121.

Mazuar, \& Burhanuddin. (2012). Studi Komparasi Perilaku Struktur Sistem Rangka Berpengaku Eksentrik Tipe D Terhadap Sistem Rangka Pemikul Momen. Teras Jurnal, 2(4), 301-309.

Meirawan, D. (2010). Trilogi Karakter Manusia Bermartabat Dan Implikasinya Pada Pendidikan. Jurnal Ilmu Pendidikan, 17(3), 189-194. 
Misdah. (2015). Pesantren Di Kalimantan Barat: Kajian Komparasi Tiga Pesantren Dalam Perspektif Manajemen. Jurnal Khatulistiwa - Journal Of Islamic Studies, 5(1), 15-31.

Muflihah. (2013). Komparasi Subjek Kalimat Verbal Aktif Dan Pasif Dalam Bahasa Arab, Inggris, Indonesia Dan Bahasa Jawa (Studi Analisis Linguistik). Arabia, 5(2), 225-238.

Muhammad, A. Bin. (2000). Iţaf Fudhalail Basyar Fi Qirā'àtil Arba' 'Asyr. Kairo: Masyhad Al-Husaini.

Mukhid, A. (2009). Self-Efficacy (Perspektif Teori Kognitif Sosial Dan Implikasinya Terhadap Pendidikan). Tadris, 4(1), 106-122.

Muttaqin, A. A. (2018). Konsep Penentuan Halal Dalam Ekonomi Islam (Studi Komparasi Hadits Riwayat Bukhari Dan Tirmidzi). Indonesia Journal Of Halal, $1(1), 15-24$.

Prasetya Irawan. (1999). Logika Dan Prosedur Penelitian. Jakarta: Stia-Lan.

Purnajaya, K. D. M., \& Merkusiwati, N. K. L. A. (2014). Analisis Komparasi Potensi Kebangkrutan Dengan Metode Z-Score Altman, Springate, Dan Zmijewski Pada Industri Kosmetik Yang Terdaftar Di Bursa Efek Indonesia. E-Jurnal Akuntansi Universitas Udayana, 48-63.

Ropik, A. (2012). Studi Komparasi Pemikiran Abul A'la Maududi Dengan Muhammad Natsir Tentang. Wardah, Xxiv(25), 173-187.

Salih, S. (1977). Mabāhis Fi “Ulūm Al-Qur”̄̄n. Beirut: Dār Al-Ilm Lil Malayin.

Setiawan, A. (2014). Prinsip Pendidikan Karakter Dalam Islam (Studi Komparasi Pemikiran Al-Ghazali Dan Burhanuddin Al-Zarnuji). Dinamika Ilmu, 14(1), 112.

Setiyawan, A. (2016). Konsep Pendidikan Menurut Al- Ghazali Dan Al-Farabi (Studi Komparasi Pemikiran). Tarbawiyah, 13(1), 51-72.

Sjafi'i, A. M. (1986). Pelajaran Tajwid. Yogyakarta: Ugm Press.

Sofyani, H., Ulum, I., Syam, D., \& L., S. W. (2012). Islamic Social Reporting Index Sebagai Model Pengukuran Kinerja Sosial Perbankan Syariah (Studi Komparasi Indonesia Dan Malaysia). Jurnal Dinamika Akuntansi, 4(1), 36-46.

Sudewi, N. L., Subagia, I. W., \& Tika, I. N. (2014). Studi Komparasi Penggunaan Model Pembelajaran Problem Based Learning (Pbl) Dan Kooperatif Tipe Group Investigation (Gi) Terhadap Hasil Belajar Berdasarkan Taksonomi Bloom. EJournal Program Pascasarjana Universitas Pendidikan Ganesha, 4(1).

Syarof, J. M. (2005). Al-Qirā'āt Al-'Asyr Al-Mutawātiroh Min Ţarīq Al-Syaţibiyah Wa Al-Durroh. Kairo: Dārul Fikri.

Wagiyem. (2016). Studi Komparasi Tentang Nikah Mut'ah Perspektif Ulama Sunni dan 
Syi'ah. Al-Maslahah, 12(2), 385-403.

Wardhanie, N. S. (2012). Analisis Internet Financial Reporting Index; Studi Komparasi Antara Perusahaan High-tech dan non High-tech di Indonesia. Jurnal Reviu Akuntansi dan Keuangan, 2(2), 287-300. 